\title{
Effectiveness of Mangrove Forest as Coastal Protection along the West Coast of Northern Peninsular Malaysia
}

\author{
Ahmad Mustafa Hashim ${ }^{\mathrm{a}}$ and Diana Bazila Shahruzzaman \\ Department of Civil and Environmental Engineering, Universiti Teknologi PETRONAS, 32610 Seri Iskandar, Perak.
}

\begin{abstract}
The effectiveness of mangrove forest as coastal protection was evidenced during Indian Ocean Tsunami (IOT) on $24^{\text {th }}$ December 2004. This paper presents the assessment on the characteristics and distribution of the mangrove forest along three northern states (Perlis, Kedah and Perak) affected by IOT 2004. At each site, the characteristics of individual tree were recorded including their species, height and diameter at breast height (DBH). A total of 52 matured trees were sampled that encompassing four species; A. marina $(\mathrm{n}=21)$, A. alba $(\mathrm{n}=7), R$. mucronata $(\mathrm{n}=20)$ and $R$. apiculata $(\mathrm{n}=4)$ were found with $A$. marina as the dominant species. The zonation of mangrove forest along the northern states revealed that Avicenniacea inhabits the frontal area. The field survey also discovered that mangrove forest along the states was generally insufficient to protect the coastal area from future tsunami. There were several rehabilitation programs that had been implemented, but not all replanting efforts were successful. Outcomes from this research provided invaluable findings for the optimum replanting scheme to ensure acceptable level of protection along Malaysia's coastline.
\end{abstract}

\section{Introduction}

\subsection{Indian Ocean Tsunami 2004}

Tsunami is one of the disastrous natural events occurred and mainly generated by the sliding of the earth's surface, namely earthquakes. Generally, tsunami is triggered by the earthquake of magnitude 6.5 and above [1]. Up to 2012, Japan was recorded as the highest frequency of tsunami occurrences with 48 events [2].

The most catastrophic event recorded in tsunami history was the Indian Ocean Tsunami which occurred on $24^{\text {th }}$ December 2004 (IOT 2004). The tsunami waves reached 13 countries including Indonesia, Sri Lanka, India, Thailand, Somalia, Burma, Maldives, Malaysia, Tanzania, Bangladesh and Kenya [3]. The epicentre of the event occurred at about $30 \mathrm{~km}$ off the West Coast of Northern Sumatra, Indonesia. The $20 \mathrm{~m}$ wave height led to about 226,000 deaths and approximately USD 9.93 billion of economic losses $[4,5,6]$. The tsunami wave had propagated to the West Coast of Peninsular Malaysia and affected five states including Perlis, Pulau Pinang, Kedah, Perak and Selangor with 63 numbers of total deaths and missing people reported [7].

\subsection{Mangrove Forest as Coastal Protection}

The effectiveness of mangrove forest as coastal protection in front of the coastal area was evidenced during the IOT 2004 [8]. The coastal properties without any protection were completely destroyed by the tsunami wave. Figure 1 illustrates how mangrove forest helps to dissipate the wave energy, hence, reducing the impact along the coastal area [9]. The importance and benefits offered by mangroves have encouraged increasing number of related research. There had been numerous mangrove rehabilitation programs and replanting initiatives for protection at affected area organized by various agencies.

However, the optimum approach or technical strategy for the mangrove replanting scheme is still under active research. Several factors govern the performance of mangrove as coastal protection which include species of the tree, characteristics of tree (height, age, diameter of stem and root, diameter at breast height), basal area and also wave characteristics $[8,10]$. Thus, this paper aim to assess the characteristics and distribution of the mangrove forest along the West Coast of Peninsular Malaysia.

\footnotetext{
a Corresponding author: mustafa_hashim@utp.edu.my
} 

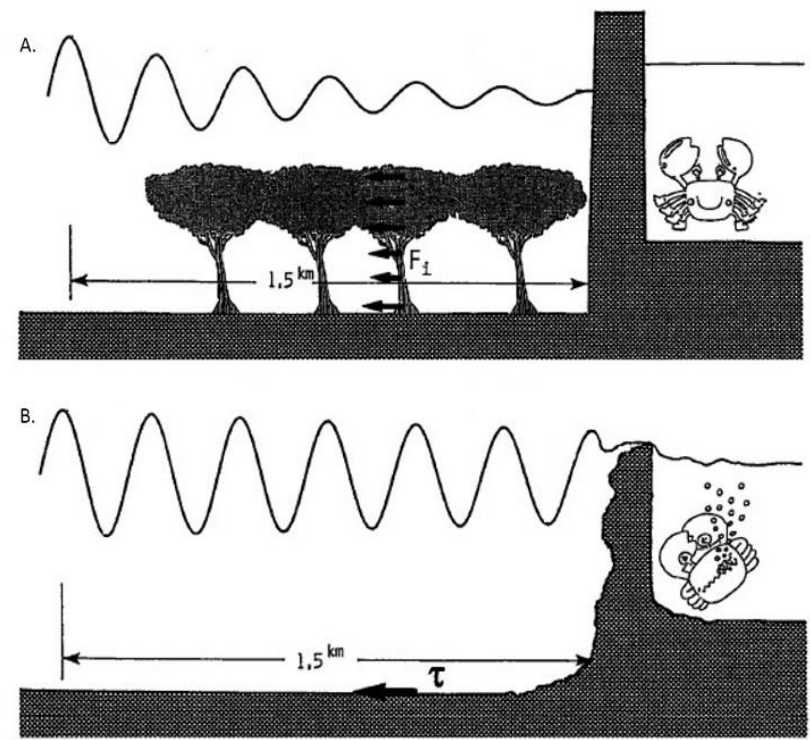

Figure 1. Wave energy and its impact at coastal area for A. With mangrove, B. Without mangrove [9].

\section{Methodology}

\subsection{Study Area}

West Coast of Peninsular Malaysia had been hit with IOT 2004. The area is bordered by the calm sea of Malacca Straits, which enabled the small particles of sediment (mud) to settle down at the coastal area [11]. Hence, the conditions contributed to the growth of mangrove forest in this part of coastline rather than the East Coast of Peninsular Malaysia [12]. However, these areas affected by the IOT 2004 are not fully recovered and potentially at high risk for future tsunami. In order to explore the current level of protection available at the previously affected IOT 2004 area, 10 sampling locations were assessed (Fig 2). These involved sites covering the three states, namely Perak (Parit Haji Dollah, Tg Kepah, Pantai Remis, Kuala Sepetang and Kuala Gula), Kedah (Pantai Merdeka, Kuala Sg Limau, Sg Ibus, Kuala Teriang) and Perlis (Kuala Sanglang).

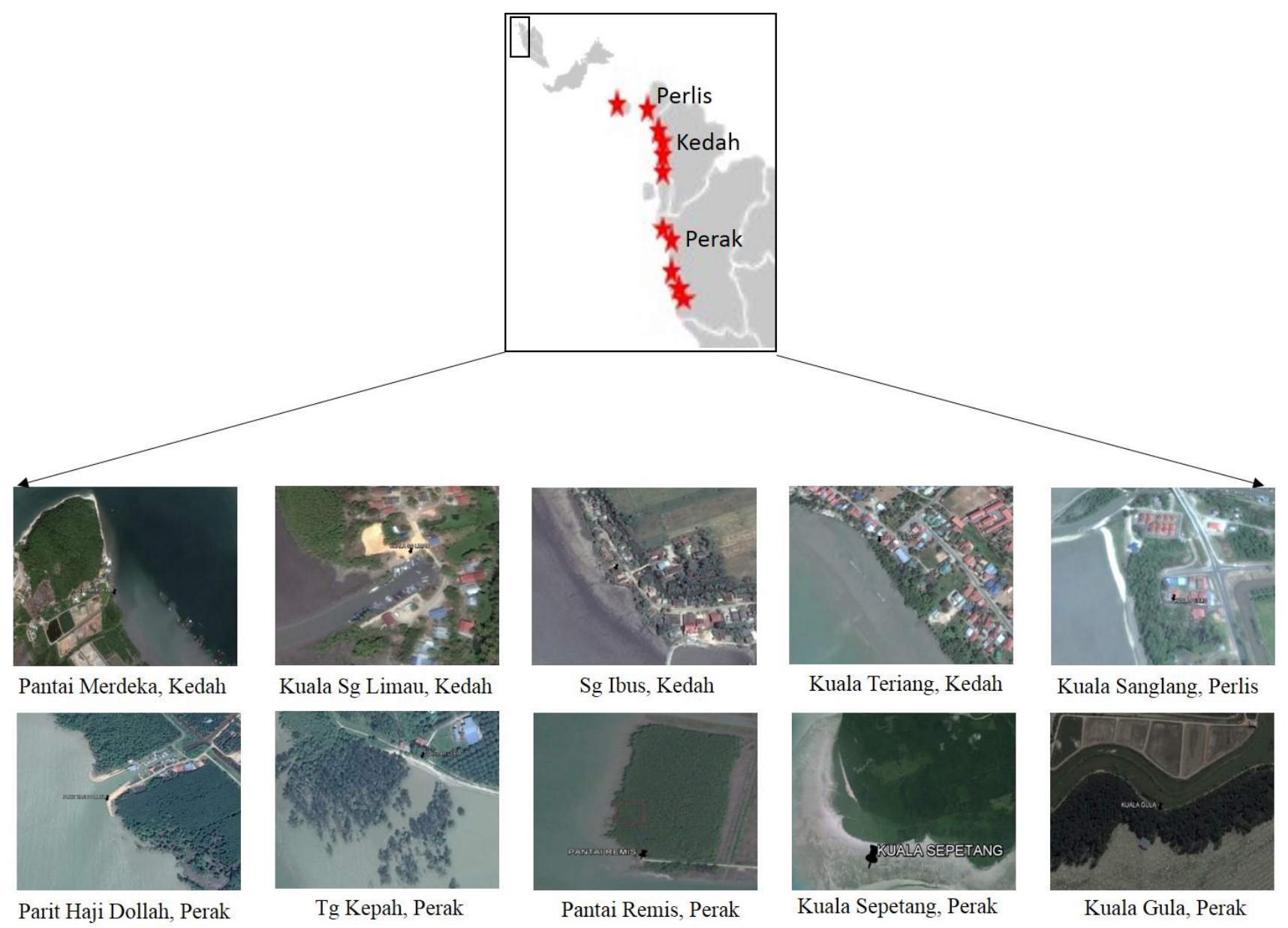

Figure 2. Locations of study area located at the coastline of Perlis, Kedah and Perak (Image adapted from Google Earth, 2016) 


\subsection{Data Collection}

The mangrove forest at each site was assessed and the time, date, coordinate and tide level were recorded. The random sampling plots $(30 \times 30 \mathrm{~m})$ were established at each site. The sampling plots were chosen as a representative of general mangrove condition for the accessed area. The selected matured trees found within the plot were identified. Measurement were carried out covering chosen trees representing different age groups. The data from selected trees were gathered include species of mangrove, basal area in $\mathrm{m}^{2}$, height of tree in $\mathrm{m}$, and diameter at breast height $(\mathrm{DBH})$ in $\mathrm{cm}$.

\subsection{Statistical Analysis}

\subsubsection{Diameter at Breast Height (DBH)}

To determine the $\mathrm{DBH}$, the circumference of the mangrove tree at $1.3 \mathrm{~m}$ height was measured at site. The DBH was calculated by using the relationship (Eq 1) stated in [13].

$$
D B H=\frac{\text { Circumfere }_{\text {nce }_{1.3}}}{\pi}
$$

Where;

Circumference $_{1.3}=$ Circumference at $1.3 \mathrm{~m}$ height

\subsubsection{Species diversity}

The ecological approach was used to determine the diversity of the mangrove forest. The relationship proposed by Shannon-Weiner (Eq 2) was used to derive the diversity index.

$$
H^{\prime}=-\sum_{i=1}^{n} P_{i} \ln P_{i}
$$

Where;

$\mathrm{P}=\mathrm{n} / \mathrm{N}$

$\mathrm{n}=$ No of individuals

$\mathrm{N}=$ Total number of mangrove tree

\section{Results and Discussion}

\subsection{Mangrove Distribution}

Mangrove forest along the coastline of Perlis, Kedah and Perak was assessed. A total of 52 matured trees from four species and two families were identified. The species included Rhizophora mucronata, Rhizophora apiculata, Avicennia alba and Avicennia marina. Table 1 shows number of the inspected mangrove trees for the respective species. They were basically divided into three age groups; (1) three to six years, (2) seven to ten years, and (3) more than 10 years. The age was categorized based on the average height of the trees. The height of the tree greatly influenced their capabilities to attenuate wave. However, young mangrove trees below two years old were not included in this study. They are easily being washed away and not able to withstand the wave action [8].

A. marina (40\%) was the dominant species found followed by $R$. mucronata (38\%), A. alba (14\%) and $R$. apiculata (8\%) (Figure 3 ). The types of mangrove found relate well with general zonation of mangrove forest. Typical zonation of the mangrove forest in Malaysia is made up of Avicennia sp. or Sonneratia sp. on the seawards most and followed by Rhizophora sp., Brugueira sp., Xylocarpus sp., and transitional dryland (Fig 4) [14, 15]. The field investigation found high number of Avicennia sp. in the visited coastal area. Avicennia sp. are able to grow seaward as they may adapt to the high salinity range from 20.9 to $31.25 \mathrm{ppt}$ [16].

Table 1. Mangrove species found at sampling plots.

\begin{tabular}{|l|c|c|c|c|}
\hline \multirow{2}{*}{ Location } & \multicolumn{2}{|c|}{ Rhizophoraceae } & \multicolumn{2}{c|}{ Avicenniaceae } \\
\cline { 2 - 5 } & $\begin{array}{c}\boldsymbol{R} . \\
\text { mucronata }\end{array}$ & $\begin{array}{c}\boldsymbol{R} . \\
\text { apiculata }\end{array}$ & $\begin{array}{c}\boldsymbol{A} . \\
\text { alba }\end{array}$ & $\begin{array}{c}\boldsymbol{A} . \\
\text { marina }\end{array}$ \\
\hline $\begin{array}{l}\text { Parit Haji } \\
\text { Dollah }\end{array}$ & 3 & 0 & 1 & 0 \\
\hline Tg Kepah & 0 & 0 & 0 & 4 \\
\hline $\begin{array}{l}\text { Kg Pantai } \\
\text { Remis }\end{array}$ & 0 & 0 & 2 & 2 \\
\hline $\begin{array}{l}\text { Kuala } \\
\text { Sepetang }\end{array}$ & 2 & 3 & 0 & 2 \\
\hline $\begin{array}{l}\text { Kg Kuala } \\
\text { Gula }\end{array}$ & 4 & 0 & 0 & 0 \\
\hline $\begin{array}{l}\text { Pantai } \\
\text { Merdeka }\end{array}$ & 3 & 0 & 0 & 1 \\
\hline $\begin{array}{l}\text { Kuala Sg } \\
\text { Limau }\end{array}$ & 0 & 0 & 3 & 1 \\
\hline Sg Ibus & 0 & 0 & 1 & 3 \\
\hline $\begin{array}{l}\text { Kuala } \\
\text { Teriang }\end{array}$ & 4 & 1 & 0 & 8 \\
\hline $\begin{array}{l}\text { Kuala } \\
\text { Sanglang }\end{array}$ & 4 & 0 & 0 & 0 \\
\hline
\end{tabular}

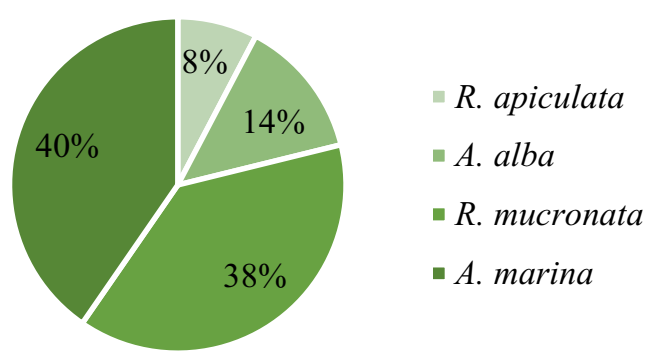

Figure 3. Distribution of mangrove forest in the surveyed coastlines. 


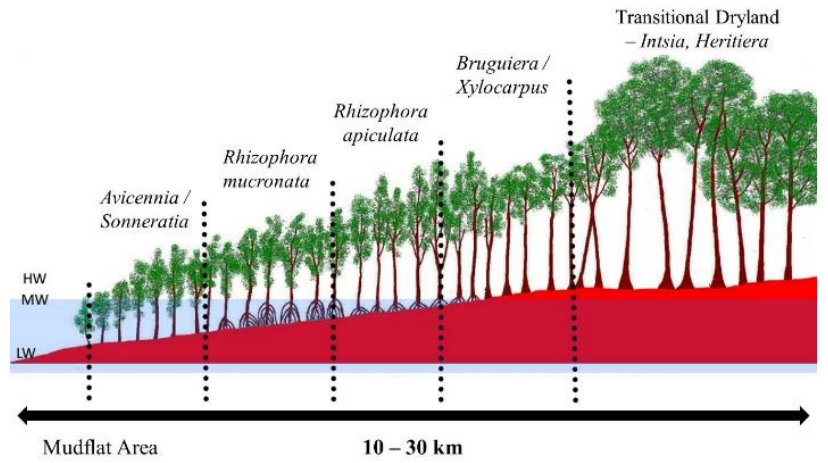

Figure 4. Typical mangrove forest zonation in Peninsular Malaysia [15].

\subsection{Condition of Mangrove Forest}

The diversity index is one of the approaches used to measure the diversity of the mangrove forest [17]. The derivation attributed from two facets including species richness and species evenness. The species diversity, evenness and richness are shown in Figure 5.

The species diversity along the coastlines was estimated to range from 0 to 1.08 . The highest species diversity found was in Kuala Sepetang with a value of 1.08. The value attributed from 3 species including $R$. mucronata, R. apiculata and A. marina. Meanwhile, the area with zero diversity indicated only one species at the representative area. The diversity of the species indicates how the area is able to attenuate wave. Different species have different wave attenuation capability [10]. Rhizophora sp. have larger and complex root and pneumatophores which enable them to create greater friction to wave as compared to other species [18].

DBH indicates as the best height to determine the tree growth. The $\mathrm{DBH}$ is also an approach to predict the dimension of the large tree $[19,20]$. The derivation from the relationship between DBH and height of the mangrove tree can be used to estimate the size of the tree [13,19]; and it indicated positive correlation as height increases with DBH (Fig 6). It is important to note that the DBH of the tree should increase with height as it grows [19].

The Pearson correlation analysis is used to reveal how strong the relationship between the variables. The value for the correlation ranges from -1 to $+1(-1 \leq \mathrm{r} \leq 1)$. Values close to +1 indicate the variables having strong positive relationship, while values close to -1 show strong negative relationship. However, value of zero implies no relationship.

It is revealed that $R$. apiculata recorded a strong correlation $(n=4 ; r=0.96)$ as compared to other species. However, analysis concluded that the growth of mangrove forest synchronises well with DBH. All the correlation coefficient values (r) are above 0.5 which indicate moderate correlation. Hence, the growth of mangrove trees are considered satisfactory.

$$
1.2
$$

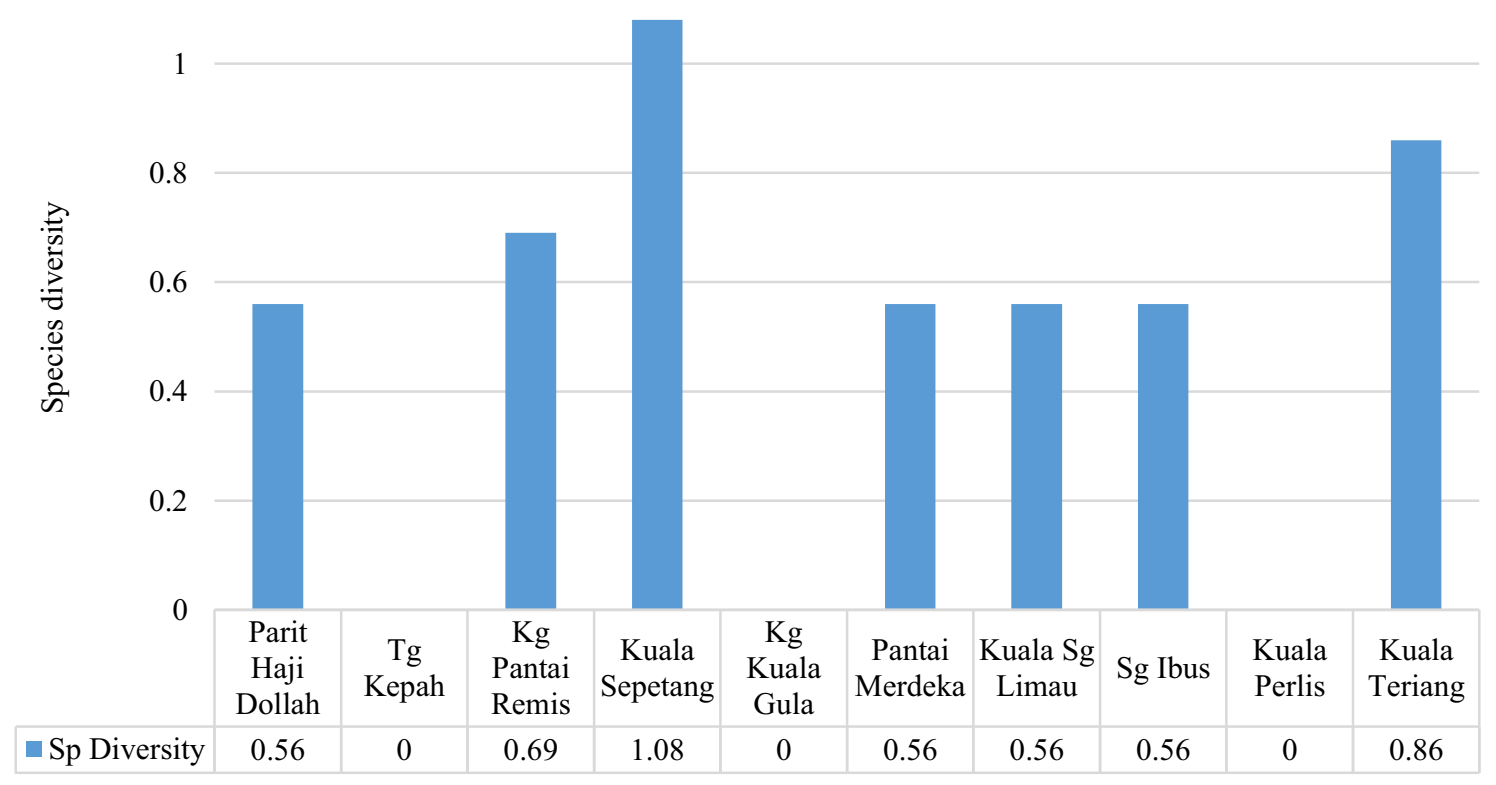

Figure 5. Species diversity of mangrove forest in the surveyed coastlines 


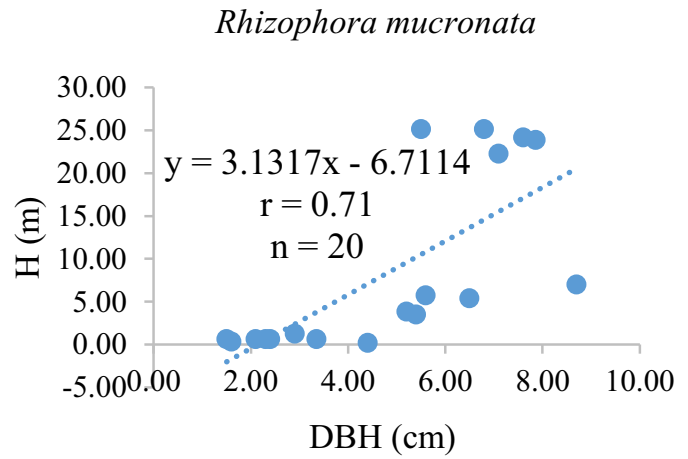

Avicennia marina

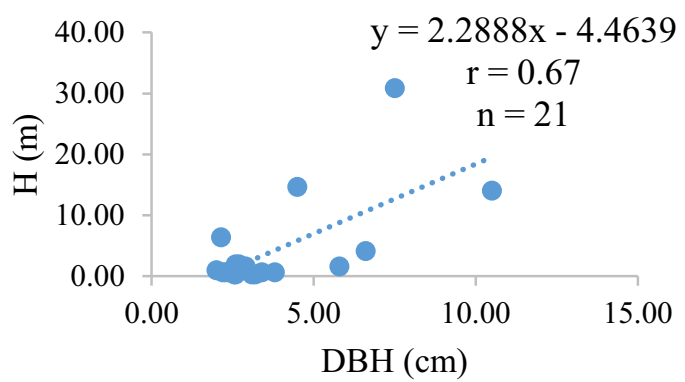

Rhizophora apiculata

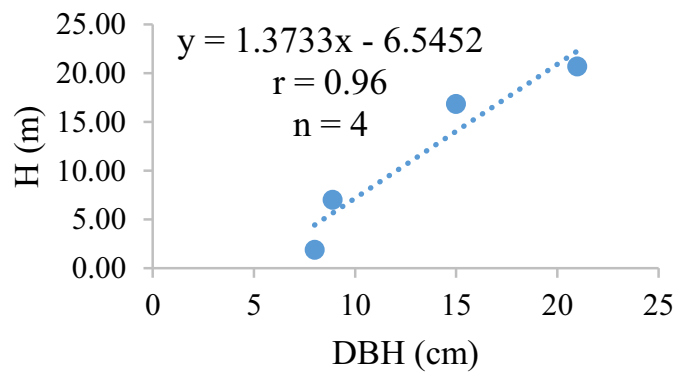

Avicennia alba

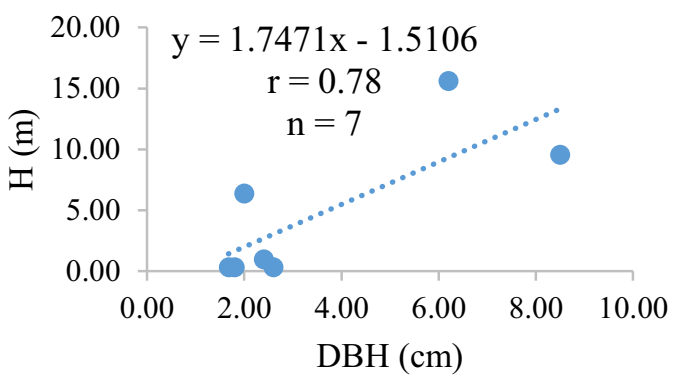

Figure 6. Correlation analysis between the height of the tree, $\mathrm{H}(\mathrm{m})$ and diameter at breast height, DBH (cm).

\subsection{Mangrove as Coastal Protection}

Mangrove forest provides countless benefits, not only to human but for ecosystem as well [21]. Unfortunately, despite the benefits offered, mangrove forest had been exploited extensively. The major factor of decreasing mangrove was due to land conversion [22]. The mangrove forest had been explored for shrimp aquaculture due to the suitability of its surrounding soil and water quality.

Analysis shows that Malaysia is exposed to some level of risk of tsunami especially at Sabah and West Coast of Peninsular Malaysia including Perlis, Penang, Kedah, Perak and Selangor (Fig 7) [15].

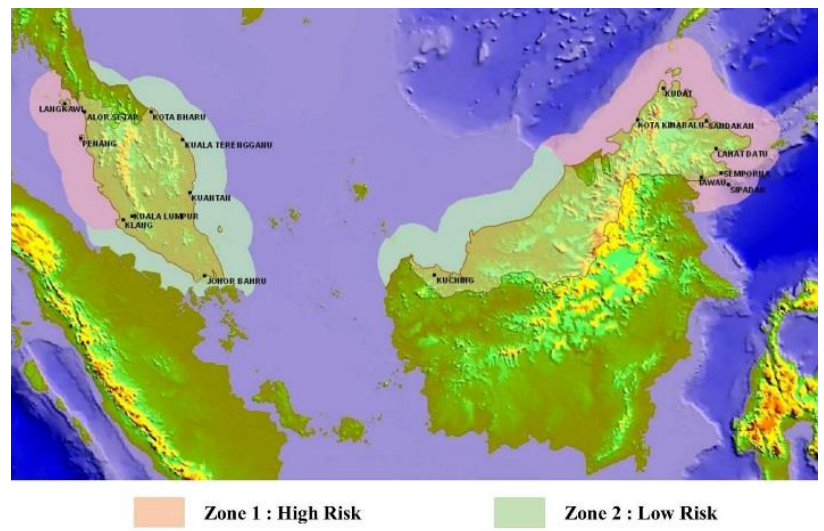

Figure 7. Map showing the tsunami risk area in Malaysia [15].

After the IOT 2004, about 1295.80 ha $(4,395,472$ number of mangrove trees) had been replanted in
Peninsular Malaysia by the relevant authorities from 2005 to 2010 (Table 2) [15]. The replantation is hoped to protect the coastal properties from wave actions.

Table 2. Locations for the rehabilitation programme in Peninsular Malaysia after IOT 2004 [15].

\begin{tabular}{|l|l|}
\hline \multicolumn{1}{|c|}{ State } & \multicolumn{1}{c|}{ Location } \\
\hline Perlis & Kuala Sanglang \\
\hline Kedah & $\begin{array}{l}\text { Kg. Huma, Tg. Dawai } \\
\text { Kota Kuala Muda }\end{array}$ \\
\hline P. Pinang & Pantai Malindo \\
\hline Perak & Lekir, Manjung \\
\hline Selangor & Bagan Nakhoda Omar \\
\hline
\end{tabular}

However, recent visit in April 2016 revealed that some of the replantation programmes were not successful. As an example, the mangroves that were replanted in Lekir, Perak in 2008 showed a retarded growth. The villagers commented that the mangrove saplings had been planted for two times, but failed. The saplings only survived for a year and later washed away after the subsequent monsoon season at the end of the year. Currently, the third attempt with two years old $R$. mucronata were planted in early 2015. However, only few trees were found to still survive, while most of the replanted trees were destroyed by the monsoon.

Remnants of the destroyed matured trees were also observed at Sg. Haji Dollah which is located south of Lekir (Fig 8). These mangroves were struggling in front of the rock revetment. It is suggested that the presence of 
revetment has led to the degradation of these trees. Mangrove trees planted behind the revetment was found to survive well.

Among the successful replanting efforts include those in Kuala Teriang, Langkawi, Kedah. The area was one of the most affected area hit by the tsunami in Peninsular Malaysia. Healthy mangrove forest grows along the coastal area from Sg Melaka to Sg Kuala Teriang (Fig 9). In front of the mangrove forest, there was an approximately $100 \mathrm{~m}$ long geotextile fabric tube placed in front of beach. The geotubes had been laid as another line of coastal protection measure for this area. Interview with local villagers described further details on the mangrove forest at site. According to one of the senior citizens residing close to the beach, the mangrove replanting was done since 2005, after the IOT 2004. The three years old $R$. mucronata were planted with about $1.3 \mathrm{~m}$ spacing. The villagers were also briefed on how to grow the mangrove tree. They were advised to plant the mangrove seedlings from the mature tree at the nursery area. This awareness campaign by the authorities allowed the mangrove to grow well at the Kuala Teriang.

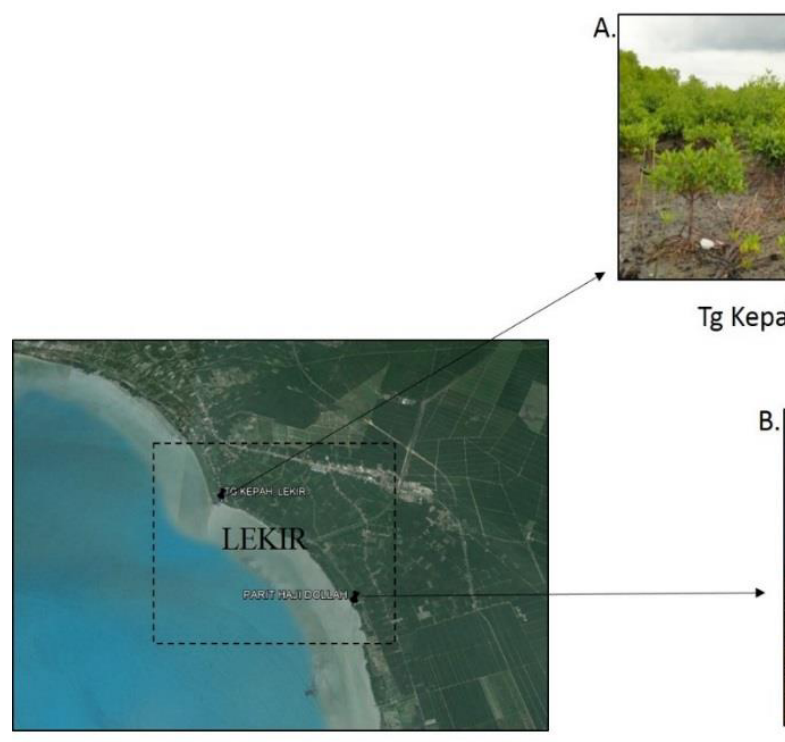

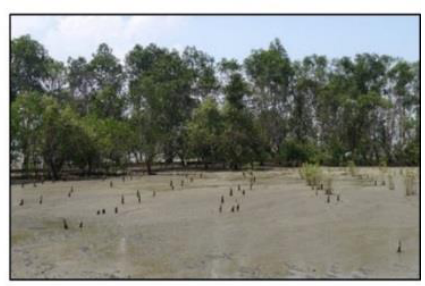

Tg Kepah, Lekir (2016)

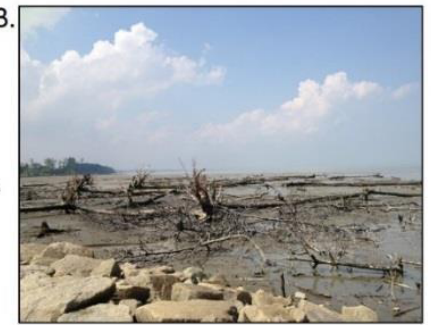

Sg Haji Dollah, Lekir (2016)

Figure 8. Replantation program implemented at Lekir, Perak, A. The replantation area in Tg Kepah. B. Fall-out of matured mangrove tree. (Image adapted from Google Earth, 2016; [15])

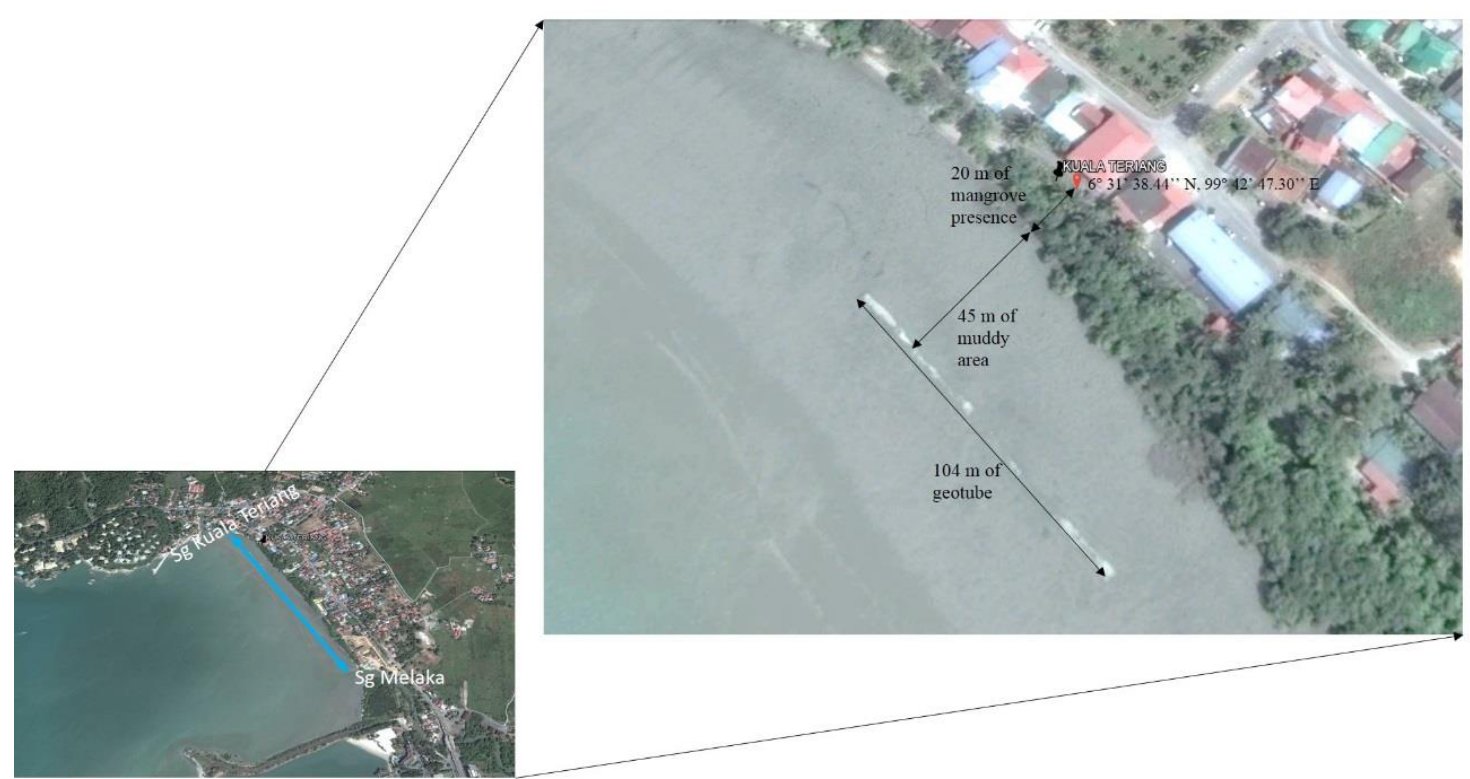

Figure 9. Geotube in front of mangrove forest at Kuala Teriang. (Image adapted from Google Earth, 2016) 


\section{Conclusion}

The IOT 2004 was the most outrageous event occurred in Malaysia with 63 numbers of total deaths. It was evidenced from the incident that the mangrove forest had contributed significantly in reducing the impacts from the wave. The unique configuration of mangrove trees enabled them to dissipate wave energy.

The field investigation shows that $A$. marina was found as the dominant species along the West Coast of Peninsular Malaysia. The zonation of mangrove forest with Avicenniaceae as frontal species contributed to this result.

However, recent field investigation also discovered that there was no sufficient mangrove belt to provide effective protection especially at the South of Perak. The replantation of mangrove forest by the authorities had experienced failures twice due to the monsoons. However, further north of Perak, the distribution of mangrove forest was found to be increasing. It is discovered that the area is one of the tourist areas under the jurisdiction of the local government. Therefore, the area was given extra attention as compared to the South of Perak. Analysis recommended that future focus should be given to the area with less mangrove forest distribution. The optimum replanting scheme should be implemented immediately to ensure safety of Malaysia's coastline from future natural disaster. This field study provides useful database which can be used for future comprehensive assessment with the aid of GIS technology and remote sensing analysis.

\section{Acknowledgement}

This research is fully supported by FRGS grant (FRGS/2/2013/TK03/UTP/02/1). The authors also wish to express special thanks to the Centre of Post Graduate Studies, Sustainable Resources MOR and Department of Civil and Environmental Engineering, Universiti Teknologi PETRONAS for their support and encouragement.

\section{References}

[1] P. Whitmore, U. t. Brink, M. Carpolo, V. HuerfanoMoreno, W. Knight, W. Sammler and A. Sandrik, NOAA/West Coast Alaska tsunami warning center atlantic ocean response criteria, Science of Tsunami Hazards, 86-107 (2009).

[2] A. Suppasri, T. Futami, S. Tabuchi and F. Imamura, Mapping of historical tsunamis in the Indian and Southwest Pacific Oceans, International Journal of Disaster Risk Reduction, 62-71 (2012)

[3] M. Z. Asmawi and A. N. Ibrahim, The impacts of tsunami on the well-being of the affected community in Kuala Muda, Kedah, Malaysia, Journal of Clean Energy Technologies, 1, 246-250 (2013)

[4] I. Fehr, P. Grossi, S. Hernandez, T. Krebs, S. McKay, R. Muir-Wood, A. Pomonis, D. C. Souch, D. Windeler and Y. Xie, Managing tsunami risk in the aftermath of the 2004 Indian Ocean earthquake and tsunami, Risk Management Solutions, Newark (2006).

[5] A. D. Hawkes, M. Bird, S. Cowie, C. Grundy-Warr, B. P. Horton, A. T. S. Hwai, C. Macgregor, J. Nott, J. Rigg, J. E. Ong, L. Law, R. Robinson, M. TanMullins, T. T. Sa, Z. Yasin and L. W. Aik, Sediments deposited by the 2004 Indian Ocean tsunami along Malaysia-Thailand Peninsula, Marine Geology, 169-190 (2007)

[6] P. C. Athukorala, Disaster, generosity and recovery: Indian Ocean Tsunami, Australian national University, Canberra (2012)

[7] K. Rostam, I. Herman and A. B. M. Nor, Kawasan penempatan semula mangsa tsunami di Malaysia: Analisis kualiti kejiranan dan kesejahteraan isi rumah, Malaysian Journal of Society and Space, 5, 33-43 (2009)

[8] D. M. Patel, V. M. Patel, K. Bhupesh and K. A. Patel, Peformance of mangrove in tsunami resistance, International Journal of Emerging Technology and Research, 1, 29-32 (2014)

[9] Y. Mazda, M. Magi, M. Kogo and P. N. Hong, Mangroves as a coastal protection from waves in the Tong King delta, Vietnam, Mangroves and Salt Marshes, 1, 127-135 (1997)

[10] Y. Mazda and M. Magi, Wave reduction in mangrove forest dominated by Sonneratia sp., Wetlands Ecology and Management, 14, 365-378 (2006)

[11] F. Alemayehu, O. Richard, K. M. James and O. Wasonga, Assessment of Mangrove Covers Change and Biomass in Mida Creek, Kenya, Journal of Forestry, 4, 398-413 (2014)

[12] N. A. Kamaruddin, S. Fujii and B. R. Shivakoti, Applicability of satellite monitoring on mangrove forests in Malaysia: A review of potential benefits and challenges, International Journal of Research, 2, 185-204 (2015)

[13] T. Buba, Relationships between Stem Diameter at Breast Height (DBH), Tree Height, Crown Length, and Crown Ratio of V. paradoxa C.F. Gaertn in the Nigerian Guinea Savanna, African Journal of Biotechnology, 12, 3441-3446 (2013)

[14] K. S. Sinfuego and I. E. Buot Jr, Mangrove zonation and utilization by the local people in Ajuy and Pedada Bays, Panay Island, Philippines, Journal of Marine and Island Cultures, 3 (2014)

[15] Y. Y. Hwai and S. Rosli, Management of mangrove forests: Policies and prescriptions, Jabatan Perhutanan Semenanjung Malaysia, Putrajaya (2012)

[16] H. Marisa and Sarno, Three Species Zonation of Sonneratia; based on Salinity in River Calik, South Sumatera, in International Conference of PLant, Marine and Environmental Sceinces (PMES-2015), Kuala Lumpur (2015) 
[17] S. Das, P. S. Lyla and S. A. Khan, Marine microbial biodiversity: Present status and advanced statistical paradigms, Conservation Biology in Asia, 368-385 (2006)

[18] K. Jusoff, Malaysian mangrove forests and their significance to the coastal marine environment, Pollution Journal Environmental Study, 22, 9791005 (2013).

[19] A. Sumida, T. Miyaura and H. Torii, Relationships between stem diameter at breast height revisited: Analyses of stem growth using 20-year data of an even-aged Chamaecyparis obtusa stand, Tree Physiology Advance, 1-13 (2013)

[20] D. W. Aheto, A. A. O. Aduomih and E. A. Obodai, Structural parameters and above-ground biomass of mangrove tree species around the Kakum river estuary of Ghana, Annals of Biological Research, 2, 504-514, (2011)

[21] A. M. Hashim and S. M. P. Catherine, A laboratory study on wave reduction by mangrove forests, APCBEE Procedia, 27-32, (2013)

[22] M. Simard, V. H. Rivera-Monroy, J. E. ManceraPineda, E. Castaneda-Moya and R. R. Twilley, A systematic method for $3 \mathrm{D}$ mapping of mangrove forests based on Shutle Radar Topography Mission elevation data, ICEsat/GLAS wavefoms and field data: Application to Cienaga Gande de Santa Marta, Colombia, Remote Sensing of Environment, 112, 2131-2144, (2008) 